\title{
Central composite experimental design applied to the catalytic carbon-sulfur bond formation by fluorapatite catalyst
}

\author{
Younes Abrouki ${ }^{1,}$, , Abdelkader Anouzla ${ }^{1}$, Hayat Loukili ${ }^{1}$, Rabiaâ Lotfi ${ }^{1}$, Ahmed Rayadh $^{1}$, \\ My Abdellah Bahlaoui ${ }^{1}$, Saïd Sebti ${ }^{2}$, Driss Zakarya ${ }^{1}$, Mohamed Zahouily ${ }^{1}$ \\ ${ }^{1}$ Department of Research, Faculty of Science and Technology, University Hassan II, Mohammedia, Morocco \\ ${ }^{2}$ Department of Chemistry, Faculty of Science Ben M'Sik, University Hassan II, Casablanca, Morocco
}

Email address:

abroukiyounes@yahoo.fr(Y. Abrouki)

To cite this article:

Younes Abrouki, Abdelkader Anouzla, Hayat Loukili, Rabiaâ Lotfi, Ahmed Rayadh, My Abdellah Bahlaoui, Saïd Sebti, Driss Zakarya, Mohamed Zahouily. Central Composite Experimental Design Applied to the Catalytic Carbon-Sulfur Bond Formation by Fluorapatite Catalyst. American Journal of Applied Chemistry. Vol. 1, No. 2, 2013, pp. 22-27. doi: 10.11648/j.ajac.20130102.12

\begin{abstract}
The aim of this study was to apply experimental design in the optimization of the thia-Michael addition reaction between chalcone derivatives and mercaptans catalyzed by Fluorapatite catalyst (FAP). The central composite design was used to design an experimental program to provide data to model the effects of various factors on reaction yield $(Y)$. The variables chosen were catalyst weight $\left(X_{1}\right)$, reaction time $\left(X_{2}\right)$ and solvent volume $\left(X_{3}\right)$. The mathematical relationship of reaction yield on the three significant independent variables can be approximated by a nonlinear polynomial model. Predicted values were found to be in good agreement with experimental values. The optimum reaction conditions $\left(\mathrm{x}_{1}=350 \mathrm{mg}, \mathrm{x}_{2}=30\right.$ min and $x_{3}=2 \mathrm{~mL}$ ) for reaction model (chalcone and thiophenol) obtained by response surface were applied to other substrates. This study has shown that central composite design could efficiently be applied for the modeling of catalytic carbon-sulfur bond formation by FAP catalyst under mild reaction condition with high yield, and it is an economical way of obtaining the maximum amount of information with the fewest number of experiments.
\end{abstract}

Keywords: Carbon-Sulfur Bond Formation, Fluorapatite, Heterogenous Catalyst, Central Composite Design, Response Surface Methodology

\section{Introduction}

Thia-Michael addition reaction is a very useful method for carbon-sulfur bond-forming in organic synthesis [1]. This reaction also plays critical roles in the biosynthesis [2] and synthesis of bioactive compounds [3] and provides a means to protect the olefinic double bond of $\alpha, \beta$-unsaturated carbonyl groups [4]. The resultant 2-sulfido carbonyl compounds undergo copper (I)-induced or oxidative thermolytic elimination of the sulfur moiety for easy regeneration of the $\alpha, \beta$-unsaturated carbonyl groups [5]. The $\beta$-sulfido carbonyl compounds serve as starting materials for $\beta$-acylvinyl cation [6] and homoenolate [7] equivalents. Thus, there have been significant efforts towards the development of methodologies for thia-Michael addition [8].

Traditionally, the 1,4-addition of mercaptans to $\alpha, \beta$-unsaturated carbonyl compounds is catalyzed by strong bases such as alkali metal alkoxides [9], hydroxides [10], and amines [11]. However the use of either strongly acidic or basic conditions [12] frequently leads to the formation of undesirable side products owing to competing reactions, such as polymerization, self-condensation and rearrangements.

Nevertheless, advantages of the heterogeneous synthesis are very interesting; reactions take place in simple and mild conditions [13]. The products obtained are generally pure and separated easily. Thus, numerous organic reactions have been carried out in solid/liquid heterogeneous media. So, several types of catalysts or solid supports have been studied, we can mention hydrotalcite [14], alumina [15], montmorillonite [16], zeolites [17], natural phosphate [18], animal bone meal [19] and hydroxyapatite [20].

In continuation of our ongoing program to develop a heterogeneous catalysis, we describe in this paper, the investigation of central composite design for modeling and optimization of the thia-Michael addition reaction between 
chalcone derivatives and mercaptans catalyzed by Fluorapatite catalyst under mild reaction condition.

\section{Materials and Methods}

\subsection{Chemicals and Instrumentations}

All commercial reagents and solvents were used without further purification. X-ray diffraction (XRD) patterns of the catalysts were obtained on a Philips 1710 diffractometer using $\mathrm{Cu}-\mathrm{K} \alpha$ radiation. Surface areas were determined at $77 \mathrm{~K}$ using a Coulter SA 31000 instrument with an automated gas volumetric method employing nitrogen as the adsorbate. NMR spectra were recorded on a Bruker ARX 300 spectrometer. Mass spectra were recorded on a VG Autospec spectrometer. FTIR spectra were recorded on an ATI Mattson-Genesis Series spectrophotometer using the $\mathrm{KBr}$ disc method.

\subsection{Preparation and Characterization of Catalyst}

\subsubsection{Preparation of the Fluorapatite}

The preparation of the Fluorapatite catalyst (FAP) was carried out by the co-precipitation method [21] using diammonium phosphate, calcium nitrate and ammonium fluoride in presence of ammonia by the following reaction:

$$
\begin{gathered}
6\left(\mathrm{NH}_{4}\right)_{2} \mathrm{HPO}_{4}+10 \mathrm{Ca}\left(\mathrm{NO}_{3}\right)_{2}+2 \mathrm{NH}_{4} \mathrm{~F}+6 \mathrm{NH}_{4} \mathrm{OH} \\
\rightarrow \mathrm{Ca}_{10}\left(\mathrm{PO}_{4}\right)_{6} \mathrm{~F}_{2}+20 \mathrm{NH}_{4}\left(\mathrm{NO}_{3}\right)+6 \mathrm{H}_{2} \mathrm{O}
\end{gathered}
$$

$250 \mathrm{~mL}$ of a solution containing $7.92 \mathrm{~g}$ of diammonium hydrogen phosphate and $1 \mathrm{~g}$ of ammonium fluoride, maintained at $\mathrm{pH}$ greater than 12 by addition of ammonium hydroxide $(15-20 \mathrm{~mL})$, were dropped under constant stirring into $150 \mathrm{~mL}$ of a solution containing $23.6 \mathrm{~g}$ calcium nitrate $\left(\mathrm{Ca}\left(\mathrm{NO}_{3}\right)_{2} \cdot 4 \mathrm{H}_{2} \mathrm{O}\right)$. The suspension was refluxed for $4 \mathrm{~h}$. Doubly distilled water (DDW) was used to prepare the solutions.

The FAP crystallites were filtered, washed with DDW, dried overnight at $80^{\circ} \mathrm{C}$ and calcined in air at $700^{\circ} \mathrm{C}$ for 30 min before use.

\subsubsection{Characterization of the Fluorapatite}

The structure of final product FAP was confirmed by $\mathrm{X}$-ray diffraction and infrared spectra. The lattice parameter of this apatite is in excellent agreement with standard data: $a=9.364$ and $9.422 \AA$ and $c=6.893$ and $6.883 \AA$.

Surface area for calcined FAP was determined by the BET method from the adsorption-desorption isotherm of nitrogen at its liquid temperature $(77 \mathrm{~K})$ and was found to be $S=15$ $\mathrm{m}^{2} \mathrm{~g}^{-1}$. The total pore volume was calculated by the BJH method at $P / P_{0}=0.98\left(V_{\mathrm{t}}=0.0576 \mathrm{~cm}^{3} / \mathrm{g}\right)$.

\subsection{General Procedure}

The general procedure is reported in Figure 1, as follows: To a flask containing an equimolar mixture $(1 \mathrm{mmol})$ of Michael donors 2 and Michael acceptors 1 in methanol catalyzed by FAP was added and the mixture was stirred at room temperature until completion of the reaction, as monitored by thin layer chromatography.

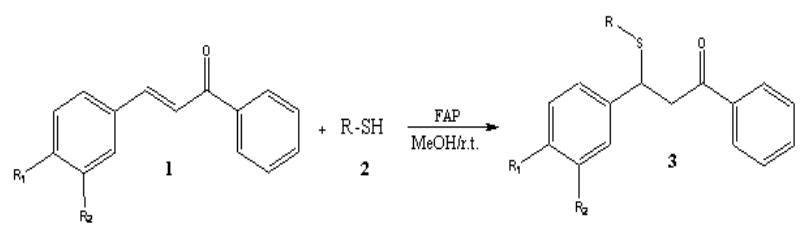

Figure 1. Thia-Michael addition reaction catalyzed by Fluorapatite

The catalyst was filtered, washed with dichloromethane and the filtrate was concentrated under reduced pressure. The crude product was purified by recrystallization. The product was analyzed by ${ }^{1} \mathrm{H},{ }^{13} \mathrm{C}$ NMR and IR spectrometry.

\subsection{Statistical Analysis}

A central composite rotatable design [22] for $k$ independent variables was employed to design the experiments in which the variance of the predicted response, $\hat{Y}$, at some points of independent variables, $X$, is only a function of the distance from the point to the design centre. The design of experiment is intended to reduce the number of experiments and to arrange the experiments with various combinations of independent variables. In the rotatable design, the standard error, which depends on the coordinates of the point on the response surface at which $\hat{Y}$ is evaluated and on the coefficients $\beta$, is the same for all points that are the same distance from the central point.

These designs consist of a $2^{k}$ factorial (coded to the usual \pm 1 notation) augmented by $2 * k$ axial points $( \pm \alpha, 0,0),(0, \pm \alpha$, $0),(0,0, \pm \alpha)$, and 2 centre points $(0,0,0)$. The value of $\alpha$ for rotatability depends on the number of points in the factorial portion of the design, which is given in Eq. (1) :

$$
\alpha=\left(N_{F}\right)^{1 / 4}
$$

Where $N_{F}$ is the number of points in the cube portion of the design $\left(N_{F}=2^{k}, k\right.$ is the number of factors). Since there are three factors, the $N_{F}$ number is equal to $2^{3}(=8)$ points, while $\alpha$ is equal to $(8)^{1 / 4}(=1.682)$ according to Eq. (1).

In this study, the response was reaction yield $\left(Y_{\mathrm{R} \%}\right)$. Each response was used to develop an empirical model that correlated the response to the reaction conditions variables for catalytic carbon-sulfur bond formation, using a second-degree polynomial equation as given by Eq. (2):

$$
\begin{aligned}
\hat{Y}= & \beta_{0}+\beta_{1} X_{1}+\beta_{2} X_{2}+\beta_{3} X_{3}+\beta_{12} X_{1} X_{2}+\beta_{13} X_{1} X_{3} \\
& +\beta_{23} X_{2} X_{3}+\beta_{11} X_{12}+\beta_{22} X_{22}+\beta_{33} X_{32}
\end{aligned}
$$

Where $\beta_{0}$ the constant coefficient, $\beta_{i}$ the linear coefficients, $\beta_{i j}$ the cross-product coefficients and $\beta_{i i}$ is the quadratic coefficients.

The software STATGRAPHICS-Plus was used for the experimental design, data analysis, model building, and graph plotting. 


\section{Results and Discussion}

\subsection{Reaction Model}

Conjugate addition between chalcone $(\mathrm{X}=\mathrm{H})$ and thiophenol $(\mathrm{R}=\mathrm{Ph})$ were chosen as model substrates to determine suitable reaction conditions for the catalytic carbon-sulfur bond formation by FAP catalyst.

\subsection{Experimental Design}

Preliminary experiments were carried out to screen the appropriate parameters and to determine the experimental domain. From these experiments, the effects of catalyst weight $\left(\mathrm{X}_{1}\right)$, reaction time $\left(\mathrm{X}_{2}\right)$ and solvent volume $\left(\mathrm{X}_{3}\right)$ are investigated on reaction yield as response. The parameter levels and coded values were given in Table 1.

Table 1. Study field and coded factors

\begin{tabular}{lcccc}
\hline \multirow{2}{*}{ Natural variable } & Unit & \multicolumn{4}{l}{ Coded variables $\mathbf{X}_{\mathbf{1}}, \mathbf{X}_{\mathbf{2}}$ and $\mathbf{X}_{\mathbf{3}}$} \\
\cline { 3 - 5 } & & $\mathbf{- 1}$ & $\mathbf{0}$ & $\mathbf{+ 1}$ \\
\hline $\mathrm{x}_{1}=$ Catalyst weight & $\mathrm{mg}$ & 200 & 400 & 600 \\
$\mathrm{X}_{2}=$ Reaction time & $\min$ & 15 & 25 & 35 \\
$\mathrm{X}_{3}=$ Solvent volume & $\mathrm{mL}$ & 1.5 & 3 & 4.5 \\
\hline
\end{tabular}

The experimental design matrix and the corresponding experimental parameters and response value were shown in Table 2.

Table 2. Experimental design and results

\begin{tabular}{|c|c|c|c|c|}
\hline \multirow{2}{*}{ Order } & \multicolumn{3}{|c|}{ Coded units of variable } & \multirow{2}{*}{ Reaction yield } \\
\hline & $\mathbf{X}_{1}$ & $\mathbf{X}_{2}$ & $\mathbf{X}_{3}$ & \\
\hline 01 & +1 & +1 & +1 & 93 \\
\hline 02 & +1 & +1 & -1 & 80 \\
\hline 03 & +1 & -1 & +1 & 67 \\
\hline 04 & +1 & -1 & -1 & 62 \\
\hline 05 & -1 & +1 & +1 & 82 \\
\hline 06 & -1 & +1 & -1 & 94 \\
\hline 07 & -1 & -1 & +1 & 39 \\
\hline 08 & -1 & -1 & -1 & 63 \\
\hline 09 & -1.682 & 0 & 0 & 72 \\
\hline 10 & +1.682 & 0 & 0 & 81 \\
\hline 11 & 0 & -1.682 & 0 & 46 \\
\hline 12 & 0 & +1.682 & 0 & 96 \\
\hline 13 & 0 & 0 & -1.682 & 78 \\
\hline 14 & 0 & 0 & +1.682 & 72 \\
\hline 15 & 0 & 0 & 0 & 94 \\
\hline 16 & 0 & 0 & 0 & 96 \\
\hline
\end{tabular}

The final empirical model in term of coded factors after excluding the insignificant terms for reaction yield $\left(\hat{\mathrm{Y}}_{\mathrm{R} \%}\right)$ is shown in Eq. (3) :

$$
\begin{aligned}
\hat{\mathrm{Y}}_{\mathrm{R} \%}= & 95,0389+2,86568 * \mathrm{X}_{1}+14,7977 * \mathrm{X}_{2}-2,0569 * \mathrm{X}_{3} \\
& -6,6346 * \mathrm{X}_{1}{ }^{2}-8,57915 * \mathrm{X}_{2}^{2}-7,16493 * \mathrm{X}_{3}^{2}-3,75 * \mathrm{X}_{1} \mathrm{X}_{2} \\
& +6,75 * \mathrm{X}_{1} \mathrm{X}_{3}+2,5 * \mathrm{X}_{2} \mathrm{X}_{3}
\end{aligned}
$$

Positive sign in front of the terms indicates synergistic effect, whereas negative sign indicates antagonistic effect. The quality of the model developed was evaluated based on the correlation coefficient value.

The $R$ value for Eq. (3) was 0.9993 . The $R$ value obtained was relatively high, indicating that there was a good agreement between the experimental and the predicted values from the model.

The $R^{2}$ value for Eq. (3) was 0.9986 . This indicated that $99.86 \%$ of the total variation in the reaction yield was attributed to the experimental variables studied. From the statistical results obtained, it was shown that the above model was adequate to predict the reaction yield within the range of variables studied.

The adequacy of the model was further justified through analysis of variance (ANOVA).

The ANOVA for model for reaction yield is listed in Table 3. From this ANOVA, the Model F-value of 540 implied that the model was significant. Values of Prob. $>F$ less than 0.01 indicated that the model terms was significant. In this case, the linear terms $\left(\mathrm{X}_{1}, \mathrm{X}_{2}\right.$ and $\left.\mathrm{X}_{3}\right)$, the squared terms $\left(\mathrm{X}_{1}^{2}, \mathrm{X}_{2}^{2}\right.$ and $\left.\mathrm{X}_{3}^{2}\right)$ and the interaction terms $\left(X_{1} X_{2}, X_{1} X_{3}\right.$ and $\left.X_{2} X_{3}\right)$ were significant model terms. It appears that all effects are significant.

Interactions between independent variables are shown in three-dimensional surface plots with other variable being at fixed level (Fig. 2 A-D).

Figure 2-A and 2-B shows the interaction between catalyst weight $\left(\mathrm{X}_{1}\right)$ and reaction time $\left(\mathrm{X}_{2}\right)$ at constant value of the solvent volume $\left(X_{3}=+1\right)$ and $\left(X_{3}=-1\right)$.

Interaction between catalyst weight $\left(\mathrm{X}_{1}\right)$ and solvent volume $\left(\mathrm{X}_{3}\right)$ at constant value of the reaction time $\left(\mathrm{X}_{2}=0\right)$ is shown in Figure 2-C.

Figure 2-D shows the interaction between reaction time $\left(\mathrm{X}_{2}\right)$ and solvent volume $\left(\mathrm{X}_{3}\right)$ at constant value of the catalyst weight $\left(\mathrm{X}_{1}=0\right)$.

\subsection{Optimizing Reaction Conditions}

The main objective of this research is to determine the best reaction conditions to conjugate addition between chalcone and thiophenol.

Then, using above-mentioned methodology for experimental design, the ranges of the parameters required to obtain optimum conditions were determined. In this optimization study, reaction yield was chosen as the objective function. Furthermore, optimum conditions are often calculated in the presence of some constraints which ensure them to be more realistic. If the model used in the optimization study is an empirical one, high and low levels 
of the process parameters in the experimental design are considered, inevitably, as explicit constraints, in order to avoid extrapolation. Thus, the optimization problem for response is defined as:

Maximize:

$$
\hat{\mathrm{Y}}_{\mathrm{R} \%}=\operatorname{Max} \hat{\mathrm{Y}}_{\mathrm{R} \%}
$$

Constraints on the parameters $X$ :

$$
-\alpha_{i}<X_{i}<+\alpha_{i} \quad i=1,2,3
$$

The investigation of equation 3 showed that, if $X_{1}=0.25$, $\mathrm{X}_{2}=0.50$ and $\mathrm{X}_{3}=-0.67$; the value predict from the results using response surface model is $98 \%$. The experimental checking in this point, i.e. under the optimum reaction conditions such as: catalyst weight $=350 \mathrm{mg}$, reaction time $=30 \mathrm{~min}$ and solvent volume $=2 \mathrm{~mL}$ with high reaction yield $96 \%$, confirms this result.

\begin{tabular}{|c|c|c|c|c|c|c|}
\hline Source of variation & Coefficient & Sum of Squares & $\mathbf{v}$ & Mean square & $F_{\text {exp }}$ & Significance test \\
\hline Regression & - & 4559.3112 & 9 & 506.59013 & 539.998974 & $*$ \\
\hline$\beta_{0}$ & 95.0389 & - & 1 & - & - & \\
\hline$\beta_{1}$ & 02.8657 & 0112.1520 & 1 & 0112.1520 & 0119.55 & $* *$ \\
\hline$\beta_{2}$ & 14.7977 & 2990.4600 & 1 & 2990.4600 & 3187.67 & $* *$ \\
\hline$\beta_{3}$ & -02.0569 & 0057.7798 & 1 & 0057.7798 & 0061.59 & $* *$ \\
\hline$\beta_{11}$ & -06.6346 & 0407.7860 & 1 & 0407.7860 & 0434.68 & $* *$ \\
\hline$\beta_{12}$ & -03.7500 & 0112.5000 & 1 & 0112.5000 & 0119.92 & $* *$ \\
\hline$\beta_{13}$ & 06.7500 & 0364.5000 & 1 & 0364.5000 & 0388.54 & $* *$ \\
\hline$\beta_{22}$ & -08.5792 & 0681.8850 & 1 & 0681.8850 & 0726.82 & $* *$ \\
\hline$\beta_{23}$ & 02.5000 & 0050.0000 & 1 & 0050.0000 & 0053.30 & $* *$ \\
\hline$\beta_{33}$ & -07.1649 & 0475.5840 & 1 & 0475.5840 & 0506.95 & $* *$ \\
\hline Residue & - & 0005.62879 & 6 & 0.9381316 & - & \\
\hline Total & - & 4564.94000 & 15 & - & - & \\
\hline
\end{tabular}

Table 3. Regression variance analysis for the model

* Significant at a level of $1 \% \mathrm{~F}_{0.01}(9.6)=7,98$

** Significant at a level of $1 \% \mathrm{~F}_{0.01}(1.6)=13,75$
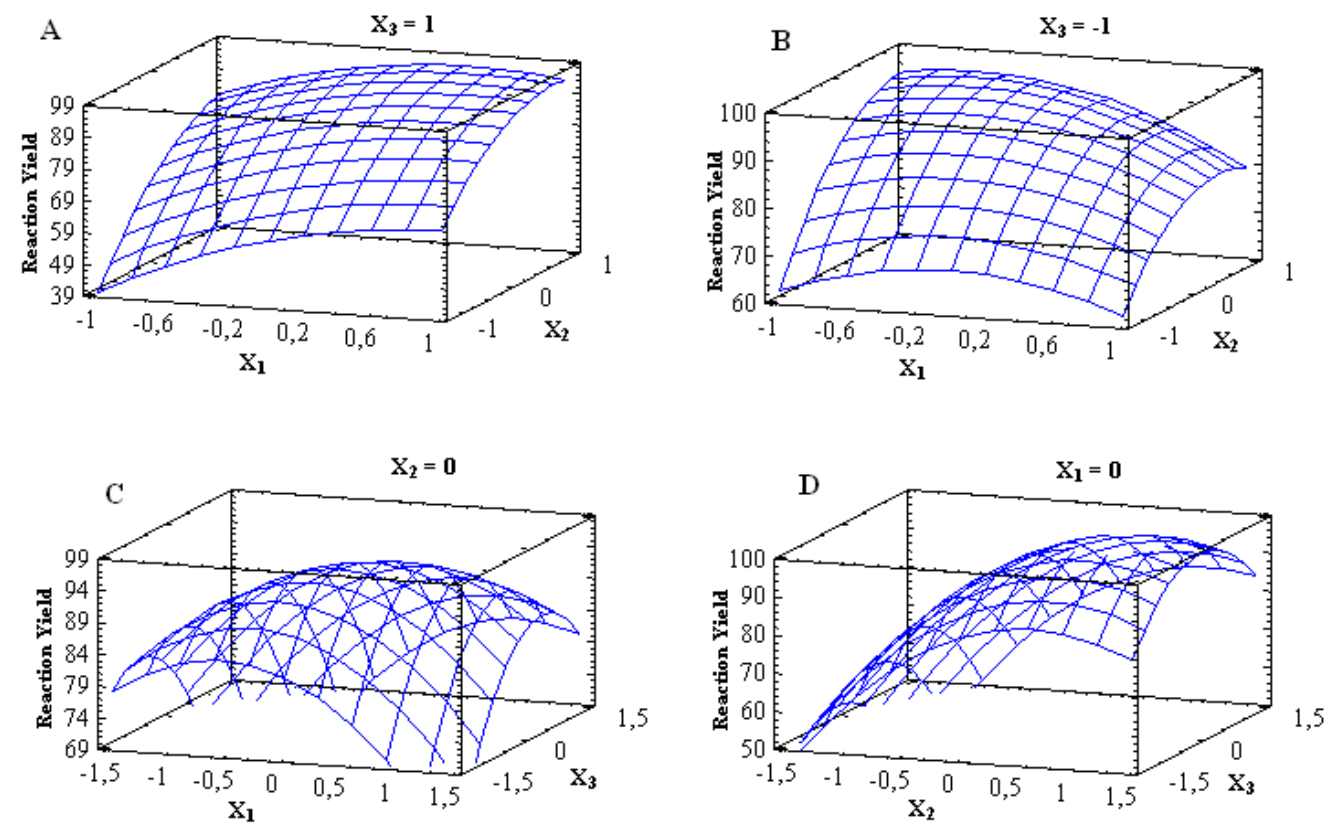

Figure 2. Response surface graphs for interactions between independent variables with other variable being at fixed level 


\subsection{Catalytic Carbon-Sulfur Bond Formation}

To determine the scope and limitation of this reaction, the optimum condensations were applied to other substrates as shown in table 34.

Several structurally varying donors(2) such as thiophenol, 2-aminothiophenol and ethyl thioglycolate underwent clean and remarkably FAP catalyst thia-Michael addition with a variety of acceptors(1) including simple and substituted chalcones.

The products of undesirable side reactions resulting from 1,2 addition, polymerization and bis-addition are not observed. The yields obtained with synthetic phosphate FAP are very high and exceed $81 \%$, except for the products (31, $3 \mathrm{~m}$ and $3 \mathrm{o}$ ). In this case, the low reactivity observed may be due to low nucleophilicity of ethyl thioglycolate or to the presence an electron-donor, the same similar effect has been observed with others solid state phosphates in heterogeneous catalysis.

The use of FAP catalyst is particularly interesting since it's regenerated by calcinations at $700^{\circ} \mathrm{C}$ during $15 \mathrm{~min}$, and after five successive recoveries, product $3 \mathrm{a}$ was obtained with same yield. Thus, we estimate that the surface of the synthetic phosphate presents certainly multicatalytic active sites.

The basic sites $\left(\mathrm{CaF}_{2}\right.$ and oxygen of $\mathrm{PO}_{4}$ group $)$ enhance the thiol nucleophilicity.

The acidic sites $\left(\mathrm{Ca}^{+}\right.$and phosphorus $\mathrm{PO}_{4}$ group) probably increase the enone moiety polarization.

Consequently, the carbon-sulfur bond formation is accelerated and the sulfanyl product is obtained by the transfer of proton.

Table 4. Synthesis of sulfanyl derivatives catalyzed by Fluorapatite

\begin{tabular}{|c|c|c|c|c|}
\hline Products & $\mathbf{R}_{1}$ & $\mathbf{R}_{\mathbf{2}}$ & $\mathbf{R}$ & Yield \% \\
\hline $3 a$ & $\mathrm{H}$ & $\mathrm{H}$ & $-\mathrm{Ph}$ & 96 \\
\hline $3 b$ & $\mathrm{H}$ & $\mathrm{H}$ & $-2-\mathrm{NH}_{2}-\mathrm{Ph}$ & 94 \\
\hline $3 c$ & $\mathrm{H}$ & $\mathrm{H}$ & $-\mathrm{CH}_{2}-\mathrm{CO}_{2}-\mathrm{Et}$ & 76 \\
\hline $3 d$ & $\mathrm{H}$ & $m-\mathrm{NO}_{2}$ & $-\mathrm{Ph}$ & 94 \\
\hline $3 e$ & $\mathrm{H}$ & $m-\mathrm{NO}_{2}$ & $-2-\mathrm{NH}_{2}-\mathrm{Ph}$ & 96 \\
\hline $3 \mathrm{f}$ & $\mathrm{H}$ & $m-\mathrm{NO}_{2}$ & $-\mathrm{CH}_{2}-\mathrm{CO}_{2}-\mathrm{Et}$ & 87 \\
\hline $3 \mathrm{~g}$ & $p-\mathrm{Cl}$ & $\mathrm{H}$ & $-\mathrm{Ph}$ & 95 \\
\hline $3 \mathrm{~h}$ & $p-\mathrm{Cl}$ & $\mathrm{H}$ & $-2-\mathrm{NH}_{2}-\mathrm{Ph}$ & 92 \\
\hline $3 i$ & $p-\mathrm{Cl}$ & $\mathrm{H}$ & $-\mathrm{CH}_{2}-\mathrm{CO}_{2}-\mathrm{Et}$ & 81 \\
\hline $3 \mathrm{j}$ & $p$-Me & $\mathrm{H}$ & $-\mathrm{Ph}$ & 83 \\
\hline $3 \mathrm{k}$ & $p$-Me & $\mathrm{H}$ & $-2-\mathrm{NH}_{2}-\mathrm{Ph}$ & 95 \\
\hline 31 & $p$-Me & $\mathrm{H}$ & $-\mathrm{CH}_{2}-\mathrm{CO}_{2}-\mathrm{Et}$ & 54 \\
\hline $3 \mathrm{~m}$ & $p$-OMe & $\mathrm{H}$ & $-\mathrm{Ph}$ & 72 \\
\hline $3 n$ & $p$-OMe & $\mathrm{H}$ & $-2-\mathrm{NH}_{2}-\mathrm{Ph}$ & 94 \\
\hline 30 & $p$-OMe & $\mathrm{H}$ & $-\mathrm{CH}_{2}-\mathrm{CO}_{2}-\mathrm{Et}$ & 48 \\
\hline
\end{tabular}

\section{Conclusion}

The use of a central composite design for the optimization of catalytic carbon-sulfur bond formation using Fluorapatite as a catalyst was found to be effective in the study of the influence of different variables on this thia-Michael addition reaction. The three variables catalyst weight, reaction time and solvent volume significantly influenced the reaction yield. The regression model adequately explained the variation in the data and significantly represented, at a $95 \%$ confidence limit, the relationship between the independent variables and the response.

The FAP catalyst showed good performance with a high yield and the separation of the catalyst is easy by simple filtration.

\section{Acknowledgements}

We are grateful to Mr. Hamid Dhimane and Mr. Marc David of Laboratoire de Chimie et Biochimie Pharmacologiques et Toxicologiques, Université René Descartes Paris-France, for his help with data analysis.

\section{References}

[1] G. Yerli, H. Gezegen, M. Ceylan, Iodine-catalyzed addition of 2-mercaptoethanol to chalcone derivatives: Synthesis of the novel $\beta$-mercapto carbonyl compounds, Org. Commun., 5, (2012), pp. 70-76.

[2] E. Fujita, Y. Nagao, Tumor inhibitors having potential for 
interaction with mercapto enzymes and/or coenzymes, Bio. org. Chem., 6, (1977), pp. 287-309.

[3] N. K. Konduru, S. Dey, M. Sajid, M. Owais, N. Ahmed, Synthesis and antibacterial and antifungal evaluation of some chalcone based sulfones and bisulfones, Euro. J. Med. Chem., 59 (2013), pp. 23-30.

[4] B.M. Trost, D.E. Keeley, New Synthetic Methods. Secoalkylative Approach to Grandisol, J. Org. Chem., 40 (1975), pp. 2013-2013.

[5] T. Cohen, A.J. Mura Jr., D.W. Shull, E.R. Fogel, R.J. Ruffner, J.R. Falck, Removal of sulfur groups from molecules by copper(I). Preparation of sulfur-substituted 1,3-dienes for the Diels-Alder reaction, J. Org. Chem., 41 (1976), pp. 3218-3219.

[6] P. Bakuzia, M.L.F. Bakuzis, Oxidative functionalization of the beta-carbon in alpha, beta-unsaturated systems. Preparation of 3-phenylthio enones, acrylates and other vinyl derivatives, J. Org. Chem., 46 (1981), pp. 235-239.

[7] J. P. Cherkauskas, T. Cohen, Carbonyl-protected beta-lithio aldehydes and ketones via reductive lithiation. A general preparative method for remarkably versatile homoenolate equivalents, J. Org. Chem., 57 (1992), pp. 6-8.

[8] M. Zahouily, H. Charki, Y. Abrouki, B. Mounir, B. Bahlaouan, A. Rayadh, S. Sebti, Natural Phosphate Modified with Sodium Nitrate: New Efficient Catalyst for the Construction of a Carbon-Sulfur and Carbon-Nitrogen Bonds, Lett. Org. Chem., 2, (2005), pp. 354-359.

[9] M. Ceylan, M. B. Gürdere, H. Gezegen, Y. Budak, Potassium-tertiary butoxide-assisted Addition of thioglycolic acid to chalcone derivatives under solvent-free conditions, Synt. Commun., 40 (2010), pp. 2598-2606.

[10] J. T. Li, Y. Cui, G. F. Chen, Z. L. Cheng, T. S. Li, Michael Addition Catalyzed by Potassium Hydroxide Under Ultrasound, Synthetic Comm., 33, (2003), pp. 353-359.

[11] H. Hiemstra, H. Wynberg, Addition of aromatic thiols to conjugated cycloalkenones, catalyzed by chiral $\beta$-hydroxy amines: A mechanistic study of homogeneous catalytic asymmetric synthesis, J. Am. Chem. Soc., 103 (1981), pp. 417-430.

[12] T. C. Wabnitz, J. B. Spencer, A General, Brønsted Acid-Catalyzed Hetero-Michael Addition of Nitrogen, Oxygen, and Sulfur Nucleophiles, Org. Lett., 12, (2003), pp.
$2141-2144$

[13] Y. Riadi, Y. Abrouki, R. Mamouni, M. El Haddad, S. Routier, G. Guillaumet, S. Lazar, New Eco-Friendly Animal Bone Meal Catalysts for Preparation of Chalcones and Aza-Michael Adducts, Chem. Central J., 6, (2012), pp. 1-7.

[14] B. M. Choudary, M. L. Kantam, C. R. V. Reddy, K. K. Rao, F. Figueras, The first example of Michael addition catalysed by modified Mg-Al hydrotalcite, J. Mol. Catal. A. Chem., 146, (1999), pp. 279-284.

[15] U. Sharma, U. Bora, R. C. Boruah, J. S. Sandhu, Alumina-promoted fast solid-phase Michael addition of enamines with conjugated enones under microwave irradiation, Tet. Lett., 43, (2002), pp. 143-145.

[16] Gaurav Sharma, Raj Kumar, Asit K. Chakraborti, A novel environmentally friendly process for carbon-sulfur bond formation catalyzed by montmorillonite clays, J. Mol. Catal. A. Chem., 263, (2007), pp. 143-148.

[17] P. Shinde, V. Mahajan, H. Borate, V. Tillu, R. Bal, A. Chandwadkar, R. Wakharkar, Li-X-type zeolite mediated Michael addition of thiols to cyclic enones and its application in the synthesis of 13-thiaprostaglandins, J. Mol. Catal. A. Chem., 216, (2004), pp. 115-119.

[18] Y. Abrouki, M. Zahouily, A. Rayadh, B. Bahlaouan, S. Sebti, A natural phosphate and doped-catalyzed Michael addition of mercaptans to $\alpha, \beta$-unsaturated carbonyl compounds, Tet. Lett., 43, (2002), pp. 8951-8953.

[19] Y. Riadi, R. Mamouni, Y. Abrouki, M. El Haddad, N. Saffaj, S. El Antri, S. Routier, G. Guillaumet, S. Lazar, Animal Bone Meal (ABM): A Novel Natural Catalyst for Thia-Michael Addition, Tet. Lett., 51, (2010), pp. 6715-6717.

[20] M. Zahouily, Y. Abrouki, B.Bahlaouan, A. Rayadh, S. Sebti, Hydroxyapatite: new efficient Catalyst for the Michael addition, Catal. Comm., 4, (2003), pp. 521-524.

[21] S. Sebti, R. Nazih, R. Tahir, L. Salhi, A. Saber, Fluorapatite: new solid catalyst of the Knoevenagel reaction in heterogeneous media without solvent, Appl. Catal. A: Gen., 197 (2000), pp. 187-190.

[22] A. Anouzla, Y. Abrouki, S. Souabi, M. Safi, H. Rhbal, Colour and COD removal of disperse Dye solution by a novel Coagulant: Application of statistical Design for the optimization and Regression analysis, J. Hazard. Mater., 166 (2009), pp. 1302-1306. 